Article

\title{
Spherical V-Fe-MCM-48: The Synthesis, Characterization and Hydrothermal Stability
}

\author{
Wang Qian, Haiqing Wang, Jin Chen and Yan Kong * \\ State Key Laboratory of Materials-Oriented Chemical Engineering, \\ College of Chemistry and Chemical Engineering, Nanjing Tech University, Nanjing 210009, China; \\ E-Mails: wqian@njtech.edu.cn (W.Q.); hiking@njtech.edu.cn (H.W.); okachen30@gmail.com (J.C.) \\ * Author to whom correspondence should be addressed; E-Mail: kongy36@njtech.edu.cn; \\ Tel./Fax: +86-25-8358-7860.
}

Academic Editor: Rafael Luque

Received: 14 February 2015 / Accepted: 31 March 2015 / Published: 14 April 2015

\begin{abstract}
Spherical MCM-48 mesoporous sieve co-doped with vanadium and iron was successfully synthesized via one-step hydrothermal method. The material was characterized by X-ray diffraction (XRD), nitrogen adsorption-desorption isotherms, inductively coupled plasma (ICP), scanning electron microscopy (SEM), transmission electron microscopy (TEM), diffuse reflectance UV-vis spectra, and X-ray photoelectron spectra (XPS) techniques. Results indicated that the V-Fe-MCM-48 showed an ordered 3D cubic mesostructure with spherical morphology, narrow pore size distribution and high specific surface area. Most of vanadium and iron atoms existing as tetrahedral $\mathrm{V}^{4+}$ and $\mathrm{Fe}^{3+}$ species were co-doped into the silicate framework. The particle sizes of V-Fe-MCM-48 were smaller and the specific area was much higher than those of of V-MCM-48. Additionally, the synthesized V-Fe-MCM-48 exhibited improved hydrothermal stability compared with the pure MCM-48.
\end{abstract}

Keywords: mesoporous sieve; MCM-48; co-doping; morphology; hydrothermal stability

\section{Introduction}

Due to high surface areas, narrow pore size distribution, and tunable pore diameters, the M41S family [1] has been intensely studied and applied to many areas such as catalysis [2], sorption [3] and so on since the first report in 1992. Owing to its three-dimensional (3D) cubic mesophase with gyroidal 
structure, MCM-48 favors much more to the mass transfer than MCM-41 [4-7] as the latter only shows the two-dimensional (2D) hexagonal mesophase [8,9]. Particularly, MCM-48 is more resistant to the pore-blocking [10].

In heterogeneous catalysis, the diffusion of reactants and products highly depend on the pore structure and morphology of catalyst [10]. For example, MCM-41 with various morphologies have been widely reported, e.g., sphere, rod, tube, etc. [11-13]. By contrast, less attention has been paid to the synthesis of MCM-48 with high quality and special morphology. One of the reasons is that the experimental conditions, including $\mathrm{pH}$, temperature, stirring rate, stirring time, aging time as well as concentration of the template, have to be controlled precisely in order to the obtain materials of desirable mesostructure and defined morphology. In most of cases, the minor changes in the synthesizing conditions may cause disastrous effect to the final product $[10,14]$.

Due to the lack of acidity/basicity and redox properties, pure mesoporous silicate materials show limited applications in the field of catalysis. Therefore, to construct catalytic active sites, considerable effort has been spent in incorporating transition metals like Ti, V, Fe, $\mathrm{Cu}, \mathrm{Ce}$ and so on [4,14-17] into the silicate framework by a variety of methods, which include one-step hydrothermal method [4,18], wet impregnation method [19], template ion-exchange method [6] and grafting method [20]. However, many methods are not desirable as they are relatively easier to induce the formation of crystalline metal oxides outside of the framework, which may result in the elution of catalytic active sites in the liquid-phase reactions. By contrast, the one-step hydrothermal method is more advantageous in this aspect because of its facile synthesis procedures and remarkable capability of incorporating heteroatoms into the framework [19,21,22].

Furthermore, the relatively poor hydrothermal stability also limits the application of mesoporous silicate materials in the liquid-phase reactions [23]. Some approaches to improve the hydrothermal stability have been reported, such as incorporating heteroatoms [24-26], $\mathrm{pH}$ adjusting [27], addition of crystal seed precursors, inorganic salts, or PVA powder [28-31].

In the cases of the incorporations of metals into the materials, the bimetallic catalyst shows more potential than monometallic catalyst due to the synergistic effect of bimetal, which may improve the final structure as well as the stability of materials to the great extent. Till now, concerning the synthesis using bimetallic dopants, there have been numerous reports on MCM-41 mesoporous sieves but only sparse reports on the MCM-48. Furthermore, when co-doped with bimetals, it remains even more difficult to obtain materials of special morphology. The precise experimental conditions are therefore demanding for the synthesis of bimetallic MCM-48 with regular morphology. In our previous studies, mesoporous sieves doped with vanadium exhibited high catalytic activity in the oxidation of aromatics, including benzene, styrene and phenol [4,32-37]. It was also reported that the incorporation of Fe(III) can enhance the hydrothermal stability of mesoporous sieves [38].

In this study, spherical MCM-48 co-doped with V and Fe was successfully synthesized based upon our work in which spherical V-MCM-48 with the particle size of ca. $500 \mathrm{~nm}$ was synthesized [4]. The obtained material was further characterized by XRD, N2 physisorption, SEM, TEM, ICP, UV-vis, and XPS techniques. The hydrothermal stability of produced V-Fe-MCM-48 was also evaluated. 


\section{Results and Discussion}

\subsection{Mesoporous Structure of V-Fe-MCM-48 Sample}

\subsubsection{XRD}

The small-angle powder XRD patterns of Si- and V-Fe-MCM-48 samples are shown in Figure 1a. Similar to that of Si-MCM-48, the pattern of V-Fe-MCM-48 exhibits an intense peak of (221) reflection and weak peaks of (220), (332) and (420) reflections, which represent the characteristics of the three-dimensional (3D) cubic $I a \overline{3} d$ mesophase. This result indicates that highly ordered mesostructure of MCM-48 is well retained which is not significantly affected by the presence of dual dopants of $\mathrm{V}$ and $\mathrm{Fe}$ in the silicate framework. Compared with Si-MCM-48, all of the peaks corresponding to V-Fe-MCM-48 shift evidently to the lower angle region suggesting an increase in unit cell parameter ( $\left.\mathrm{a}_{0}\right)$ which may be attributed to the replacement of $\mathrm{Si}^{4+}$ (Pauling radius $=42 \mathrm{pm}$ ) by $\mathrm{V}^{4+}$ $($ Pauling radius $=58 \mathrm{pm})$ and $\mathrm{Fe}^{3+}($ Pauling radius $=64 \mathrm{pm})[35,39]$.

The wide-angle XRD pattern of the V-Fe-MCM-48 sample as showed in Figure $1 \mathrm{~b}$ exhibits a broad peak at $2 \theta \approx 23.0^{\circ}$, which is normally ascribed to the characteristic peak of amorphous silica. Beyond that, no characteristic peaks of vanadium oxide and iron oxide are observed suggesting that the sample co-doped with $\mathrm{V}$ and $\mathrm{Fe}$ atoms still exists as amorphous state without pronounced aggregation and formation of bulk crystals of metal species. We reason that both the $\mathrm{V}$ and $\mathrm{Fe}$ atoms may be incorporated into the silicate framework or highly dispersed on the surface of mesoporous channels.
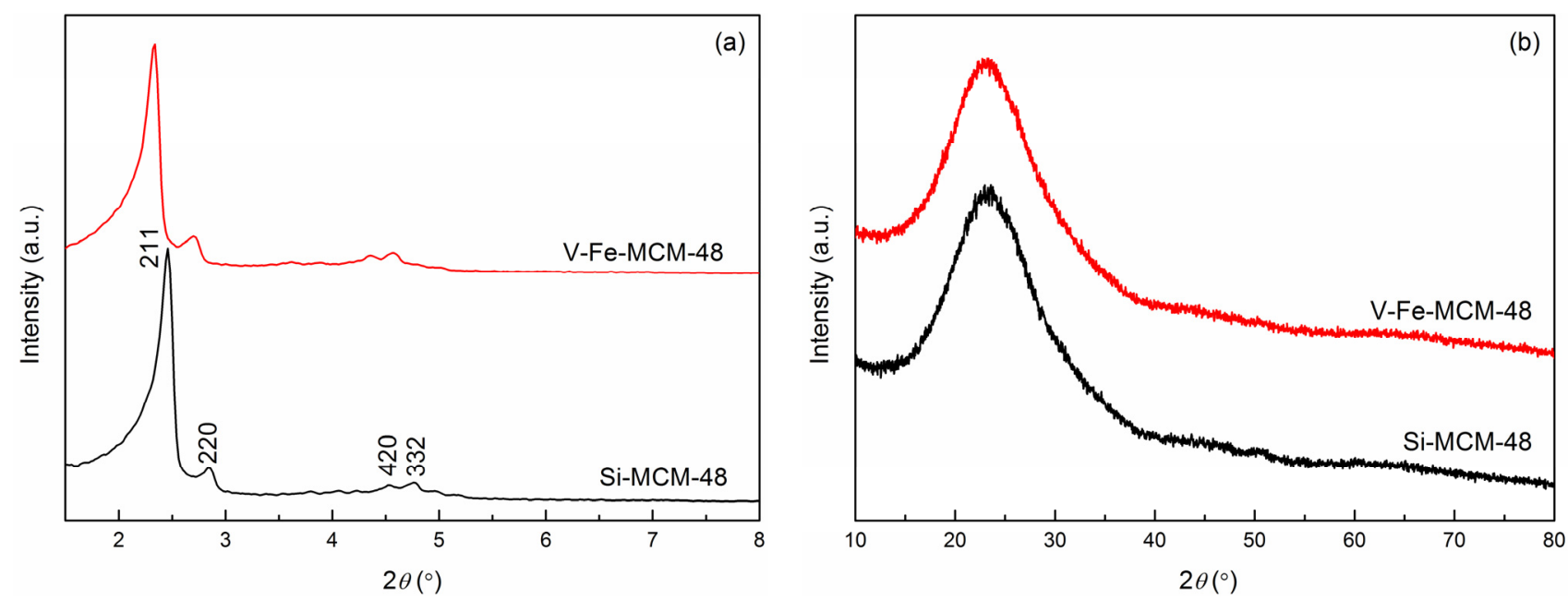

Figure 1. (a) Small-angle X-ray diffraction (XRD) patterns and (b) wide-angle XRD patterns of the calcined Si- and V-Fe-MCM-48 samples.

\subsubsection{Nitrogen Adsorption-Desorption}

The nitrogen adsorption-desorption isotherms and pore size distribution (PSD) of the calcined Siand V-Fe-MCM-48 are displayed in Figure 2. It is observed that the V-Fe-MCM-48 sample exhibits a similar type as the Si-MCM-48, which can be classified to the type IV isotherm according to the IUPAC classification [40]. A sharp step at the relative pressure of $\mathrm{p} / \mathrm{p}_{0}$ in the range of $0.20-0.35$ corresponding to the capillary condensation in channel-type mesopores suggests a high quality mesostructure and a 
narrow pore size distribution (2-3 nm) of obtained sample. However, the step of V-Fe-MCM-48 is less steep than that of Si-MCM-48 and the inflection point of step shifts to a higher relative pressure. This observation indicates that the presence of co-dopants of $\mathrm{V}$ and $\mathrm{Fe}$ decreases the order of final mesostructure and increases the pore size of materials, which is well consistent to the small-angle XRD results.

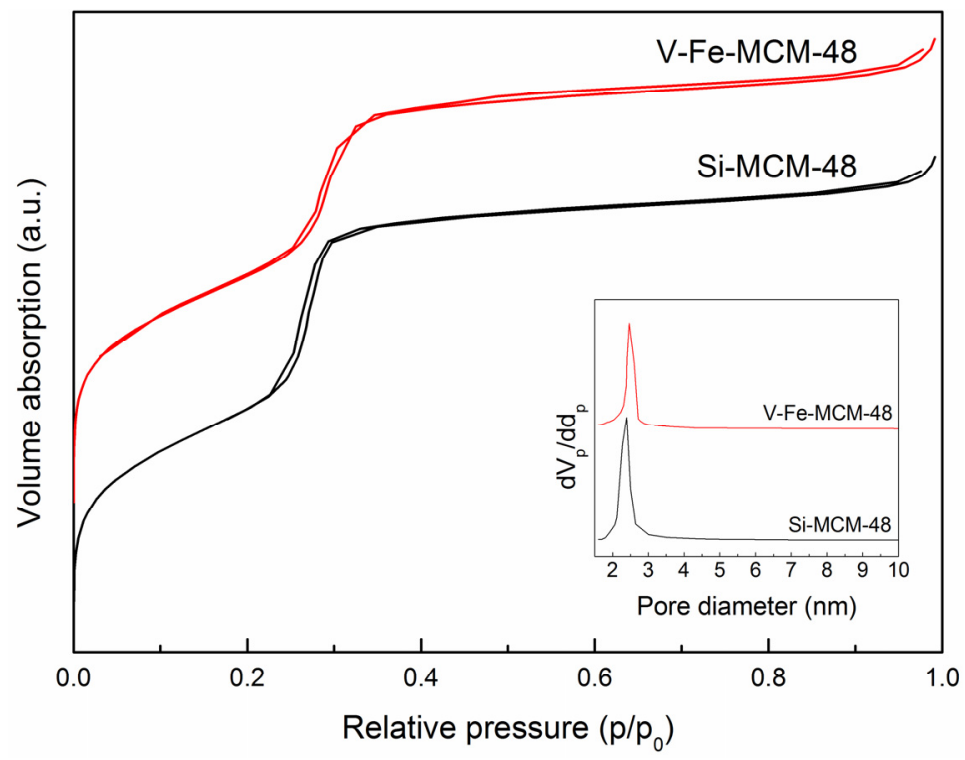

Figure 2. Nitrogen adsorption-desorption isotherms of the calcined Si- and V-Fe-MCM-48 samples. The inset shows the pore size distribution (PSD).

Table 1 shows the textural and structural parameters of the calcined Si- and V-Fe-MCM-48 samples. Compared with that of Si-MCM-48, the specific surface area (as,BET) of V-Fe-MCM-48 decreases, which is due to a partial disruption of framework caused by the co-dopants of $\mathrm{V}$ and $\mathrm{Fe}$. Nevertheless, it still shows high specific surface area over $1000 \mathrm{~m}^{2} / \mathrm{g}$. The unit cell parameter (a0) increases from 8.80 to $9.33 \mathrm{~nm}$ indicating the incorporation of $\mathrm{V}$ and $\mathrm{Fe}$ in the silicate framework, which is in good agreement with the small-angle XRD results. Notably, the wall thickness ( $\left.\mathrm{t}_{\mathrm{w}}\right)$ exhibits a remarkable increase from $1.65 \mathrm{~nm}$ to $1.79 \mathrm{~nm}$. This finding demonstrates that some metal species may be highly dispersed on the surface of mesoporous channels although they escape from the wide-angle XRD detection.

Table 1. Textural and structural parameters of the calcined Si- and V-Fe-MCM-48 samples.

\begin{tabular}{|c|c|c|c|c|c|c|c|c|c|c|}
\hline Sample & $\begin{array}{c}\mathrm{V} / \mathrm{Si}^{\mathrm{a}} \\
\text { (Molar Ratio) }\end{array}$ & $\begin{array}{c}\mathbf{V} / \mathbf{S i}^{\mathbf{b}} \\
\text { (Molar Ratio) } \\
\end{array}$ & $\begin{array}{c}\mathrm{Fe} / \mathrm{Si}^{\text {a }} \\
\text { (Molar Ratio) }\end{array}$ & $\begin{array}{c}\mathrm{Fe} / \mathrm{Si}^{\mathrm{b}} \\
\text { (Molar Ratio) } \\
\end{array}$ & $\begin{array}{c}d_{211} \\
(n m)\end{array}$ & $\begin{array}{c}\mathbf{a}_{0}{ }^{c} \\
(\mathrm{~nm}) \\
\end{array}$ & $\begin{array}{l}d_{p}^{d} \\
(n m) \\
\end{array}$ & $\begin{array}{l}\mathbf{a}_{\mathrm{s}, \mathrm{BET}} \\
\left(\mathrm{m}^{2} / \mathrm{g}\right) \\
\end{array}$ & $\begin{array}{c}\mathbf{t}_{\mathrm{w}}{ }^{\mathrm{e}} \\
(\mathbf{n m})\end{array}$ & $\begin{array}{c}V_{p} \\
\left(\mathrm{~cm}^{3} / \mathbf{g}\right) \\
\end{array}$ \\
\hline Si-MCM-48 & - & - & - & - & 3.59 & 8.80 & 2.39 & 1369.4 & 1.65 & 0.832 \\
\hline V-Fe-MCM-48 & 0.0296 & 0.0066 & 0.0062 & 0.0021 & 3.81 & 9.33 & 2.46 & 1213.2 & 1.79 & 0.777 \\
\hline
\end{tabular}

Notes: ${ }^{\text {a }}$ ICP results; ${ }^{\mathrm{b}}$ XPS results; ${ }^{\mathrm{c}}$ Unit cell parameter: $\mathrm{a} 0=66^{1 / 2} \mathrm{~d}_{211}$; ${ }^{\mathrm{d}}$ Pore diameter determined by BJH method using the desorption branch; ${ }^{\mathrm{e}}$ Wall thickness: $\mathrm{t}_{\mathrm{w}}=\mathrm{a} 0 / 3.0919-\mathrm{d}_{\mathrm{p}} / 2$.

\subsubsection{SEM and TEM}

The SEM and TEM images of the calcined V-Fe-MCM-48 sample are displayed in Figure 3. From the SEM image, it is clearly observed that the particles of V-Fe-MCM-48 synthesized in this study 
show a spherical morphology with most of particles size distribution in the range of $150-250 \mathrm{~nm}$, which is confirmed from the TEM image. It is notably that the introduction of iron species reduced the particle sizes. Meanwhile, the specific area increases significantly from 788 of V-MCM-48 [4] to $1213 \mathrm{~m}^{2} / \mathrm{g}$ of $\mathrm{V}-\mathrm{Fe}-\mathrm{MCM}-48$ with almost the same amount of vanadium species. Nevertheless, catalyst with higher surface area can be expected more superior activity.
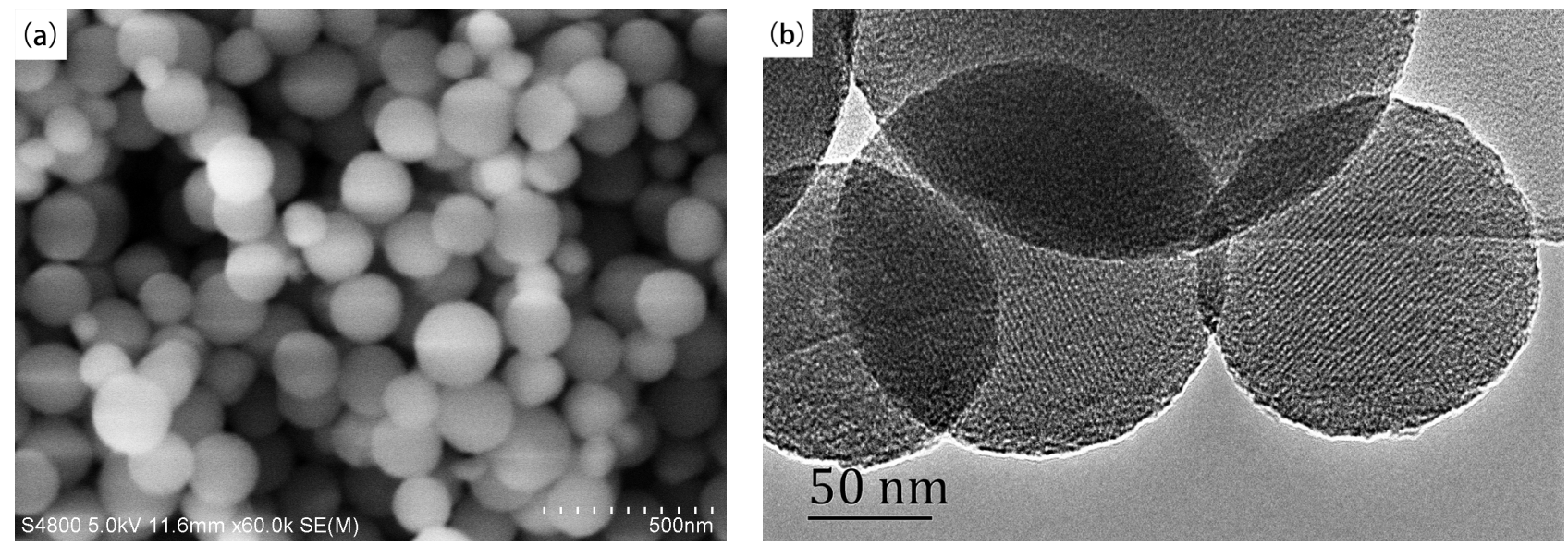

Figure 3. (a) Scanning electron microscopy (SEM) image and (b) transmission electron microscopy (TEM) image of the calcined V-Fe-MCM-48 sample.

It has been reported that vanadium species mainly exist as $\mathrm{HVO}_{4}{ }^{2-}$ and $\mathrm{V}_{2} \mathrm{O}_{7}{ }^{4-}$ when the $\mathrm{pH}$ value is in the range of 10-13 [41]. In our previous report [4], we have ascribed the formation of spherical V-MCM-48 particles to low concentration of $\mathrm{V}_{2} \mathrm{O}_{7}{ }^{4-}$ which minimizes the surface free energy, and the particles favors to become irregular in the presence of high concentration of $\mathrm{V}_{2} \mathrm{O}_{7}{ }^{4-}$. In the synthesis condition of present work, most of the vanadium species exist as $\mathrm{HVO}_{4}{ }^{2-}$, which shows lower ionic diameter than that of $\mathrm{V}_{2} \mathrm{O}_{7}{ }^{4-}$. Meanwhile, the co-dopant of $\mathrm{Fe}$ accelerates the generation of more nuclei, which results in more small crystal growth [42-45]. In this way, smaller spherical V-Fe-MCM-48 particles are generated.

\subsection{Statues of Heteroatoms}

\subsubsection{UV-Vis}

UV-vis spectra are widely used to investigate the coordination circumstance and oxidation states of metal ions. As shown in Figure 4, all the samples show an absorption band centered at $216 \mathrm{~nm}$, which is attributed to the characteristic absorption of the silica materials [46]. For the calcined V-MCM-48 sample, another two absorption bands are additionally observed in the wavelength range of 220-320 nm and 350-400 nm centered at $264 \mathrm{~nm}$ and $374 \mathrm{~nm}$, respectively. The absorption at $264 \mathrm{~nm}$ represents the charge-transfer transitions between oxygen ligands and $\mathrm{V}^{4+}$ in isolated tetrahedral coordination $\mathrm{VO}_{4}$ species, which supports that $\mathrm{V}$ atoms have been successfully incorporated into the silicate framework. The band centered at $374 \mathrm{~nm}$ is assigned to extra-framework $\mathrm{V}^{5+}$ species in distorted octahedral coordination [47]. This observation is possibly due to the interaction between $\mathrm{V}$ and water molecules in the atmosphere forming polymeric $\mathrm{V}-\mathrm{O}-\mathrm{V}$ bonds. The band of bulk $\mathrm{V}_{2} \mathrm{O}_{5}$ crystallites (ca. $450-480 \mathrm{~nm}$ ) is absent agreeing well with the wide-angle XRD results. Unlike the calcined 
V-MCM-48 sample, the calcined 1Fe-MCM-48 sample shows only one absorption peak at $254 \mathrm{~nm}$, which is attributed to the charge-transfer transitions between oxygen ligands and $\mathrm{Fe}^{3+}$ in isolated tetrahedral coordination $\mathrm{FeO}_{4}$ species [48]. In addition, there is no obvious absorption band at 500-600 nm, which represents octahedral coordination $\mathrm{Fe}^{3+}$ species in extra-framework [49]. We conclude that most of $\mathrm{Fe}^{3+}$ species are incorporated into the silicate framework. For sample co-doped with $\mathrm{V}$ and $\mathrm{Fe}$, three absorption bands centered at $216 \mathrm{~nm}, 264 \mathrm{~nm}$, and $374 \mathrm{~nm}$ are visible, which resembles that of V-MCM-48. This indicates the introduction of Fe does not affect the coordination circumstance of $\mathrm{V}$. Additionally, there may be an overlap in the 254 and $264 \mathrm{~nm}$ bands, implying that Fe may be also well incorporated into the silicate framework as the isolated tetrahedral coordination $\mathrm{Fe}^{3+}$ species.

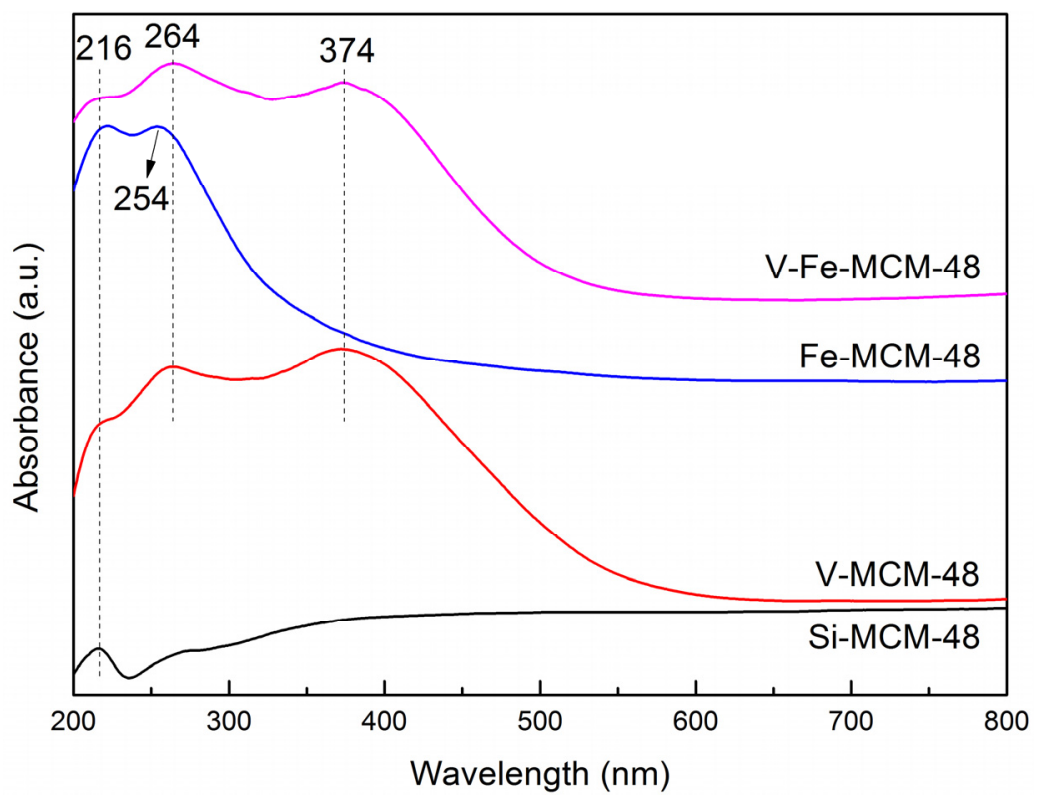

Figure 4. UV-vis spectra of calcined samples.

\subsubsection{XPS}

Because in the wide-angle XRD patterns peaks corresponding to the bulk $\mathrm{V}_{2} \mathrm{O}_{5}$ and $\mathrm{Fe}_{2} \mathrm{O}_{3}$ are absent, we further use XPS to evaluate the surface composition and the chemical states of vanadium and iron species. As shown in Figure 5a, the XPS spectrum of the V 2p region of the V-Fe-MCM-48 sample can be deconvoluted into two components centered at $517.6 \mathrm{eV}$ (A) and $516.6 \mathrm{eV}$ (B), respectively. The component $A$ is in good agreement with the $\mathrm{V} 2 \mathrm{p}_{3 / 2}$ observed for $\mathrm{V}_{2} \mathrm{O}_{5}$ indicating that vanadium exists on the exposed surface as $\mathrm{V}^{5+}$. While the component $\mathrm{B}$ cannot be clearly assigned to $\mathrm{V}^{4+}$ or $\mathrm{V}^{3+}$ based solely on the absolute value of binding energy [50]. Alternatively, the component $\mathrm{B}$ is assigned based on the differences in the binding energies $(\triangle \mathrm{BE})$. It was reported that $\triangle \mathrm{BE}$ between $\mathrm{V}^{5+}$ and $\mathrm{V}^{4+}$ is $0.7-1.0 \mathrm{eV}$, and $1.2-1.5 \mathrm{eV}$ between $\mathrm{V}^{5+}$ and $\mathrm{V}^{3+}$. The $\Delta \mathrm{BE}$ between the component $\mathrm{A}$ and $\mathrm{B}$ obtained from the present study is $1.0 \mathrm{eV}$ suggesting that the component $\mathrm{B}$ corresponds to $\mathrm{V}^{4+}$, which is agree well with the UV-vis results. Furthermore, it is observed that the peak area of $\mathrm{V}^{4+}$ is approximately twice that of $\mathrm{V}^{5+}$, and as shown in Table 1 , the content of bulk vanadium in V-Fe-MCM-48 sample determined by ICP is much higher than that of vanadium exposed on the surface obtained from XPS. These results indicate that most of vanadium atoms are doped into the silicate framework. Figure $5 \mathrm{~b}$ is the XPS spectrum of the Fe $2 p$ region of the V-Fe-MCM-48. 
The peaks at $711.7 \mathrm{eV}$ and $725.0 \mathrm{eV}$ correspond to $\mathrm{Fe} 2 \mathrm{p}_{3 / 2}$ and $\mathrm{Fe} 2 \mathrm{p}_{1 / 2}$, respectively. The existence of satellite peak centered at $720.5 \mathrm{eV}$ suggests that iron exists as $\mathrm{Fe}^{3+}$ in the sample. The binding energy value of $\mathrm{Fe} 2 \mathrm{p}_{3} / 2$ obtained here is much larger than that of pure $\mathrm{Fe}_{2} \mathrm{O}_{3}$, which has been reported between 710.6 and $711.2 \mathrm{eV}$ [51,52]. This result indicates that the iron atoms are surrounded by silicon.
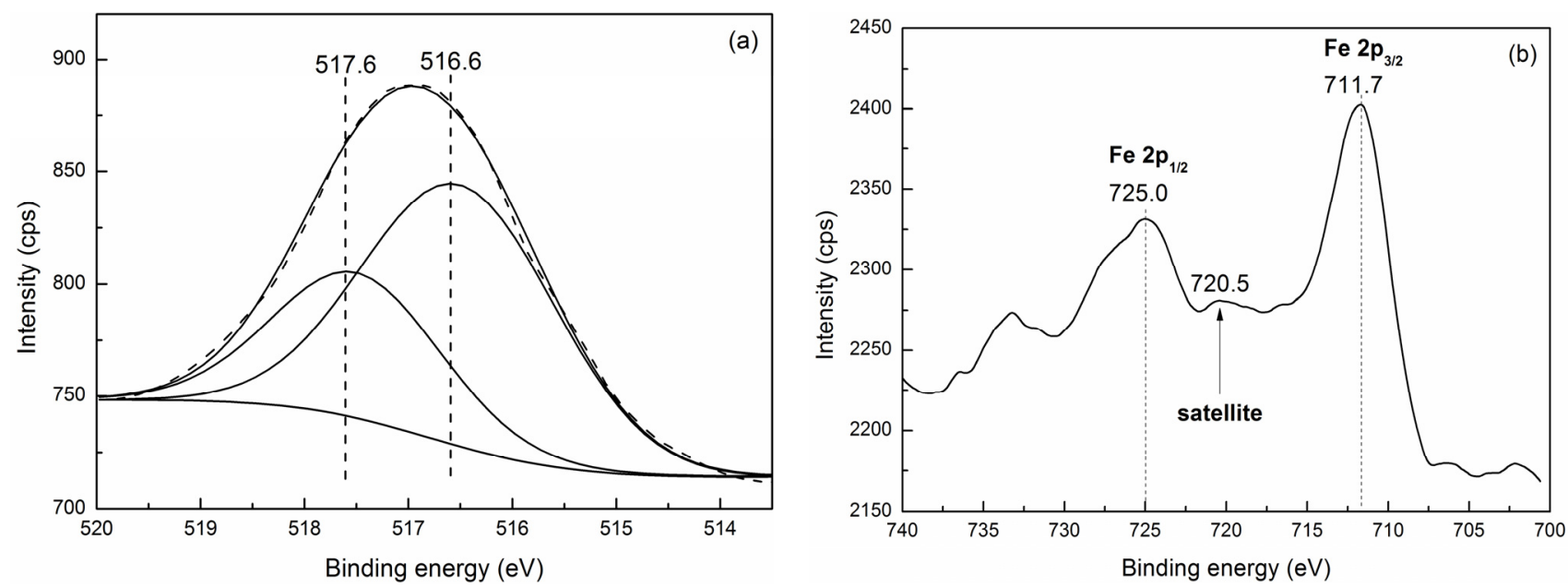

Figure 5. X-ray photoelectron spectra (XPS) of (a) V 2 $\mathrm{p}_{3 / 2}$ and (b) Fe $2 \mathrm{p}$ from the calcined V-Fe-MCM-48 sample.

\subsection{Hydrothermal Stability Test}

The hydrothermal stability of calcined $\mathrm{Si}$ - and V-Fe-MCM-48 samples treated at $110{ }^{\circ} \mathrm{C}$ for different time are evaluated by XRD. As shown in Figure 6a, the Si-MCM-48 still exhibits the (211) peak after treated for $24 \mathrm{~h}$, whereas the (220) peak was not pronounced and the (420) and (332) peaks fully disappeared indicating that mesostructured turns to be less ordered. After $48 \mathrm{~h}$ treatment, the (220) peak fully disappears and the (211) peak is getting weak and broad implying that the 3D cubic mesostructure collapses to some extent. Therefore, the Si-MCM-48 exhibits a poor hydrothermal stability. This finding is probably due to the formation of hydrogen bonds between water molecules and the $\mathrm{O}$ atoms in $\mathrm{Si}-\mathrm{O}-\mathrm{Si}$, which weakens the interaction between $\mathrm{Si}$ and $\mathrm{O}$ atoms and causes a breakage of $\mathrm{Si}-\mathrm{O}-\mathrm{Si}$ bonds. Consequently, some Si atoms may be detached from the framework, which brings some defect or collapse in the framework. For V-Fe-MCM-48 recorded in Figure 6b, the (220), (420) and (332) peaks are still visible after the treatment of $24 \mathrm{~h}$ indicating that the $3 \mathrm{D}$ cubic mesostructure of MCM-48 maintains highly ordered. The (420) and (332) peaks do not disappear until treated after $48 \mathrm{~h}$. After further treatment of $72 \mathrm{~h}$, the (220) peak is getting much more weak and almost invisible after $96 \mathrm{~h}$ treatment when the (211) peak is weak and broad. This implies that the 3D cubic mesostructure collapses.

To investigate the extent of loss of the ordered mesoporous structure with hydrothermal treating time, TEM of V-Fe-MCM-48 treated for $72 \mathrm{~h}$ has been done. As displayed in Figure 7, the sample treated for $72 \mathrm{~h}$ shows much more disordered mesoporous structure when compared with that of the $\mathrm{V}-\mathrm{Fe}-\mathrm{MCM}-48$ with no treatment exhibited in Figure 3b, which is consistent well with the small-angle XRD patterns. Furthermore, the particles severely aggregated which may be due to the polymerization of surface $\mathrm{Si}-\mathrm{OH}$ groups. 

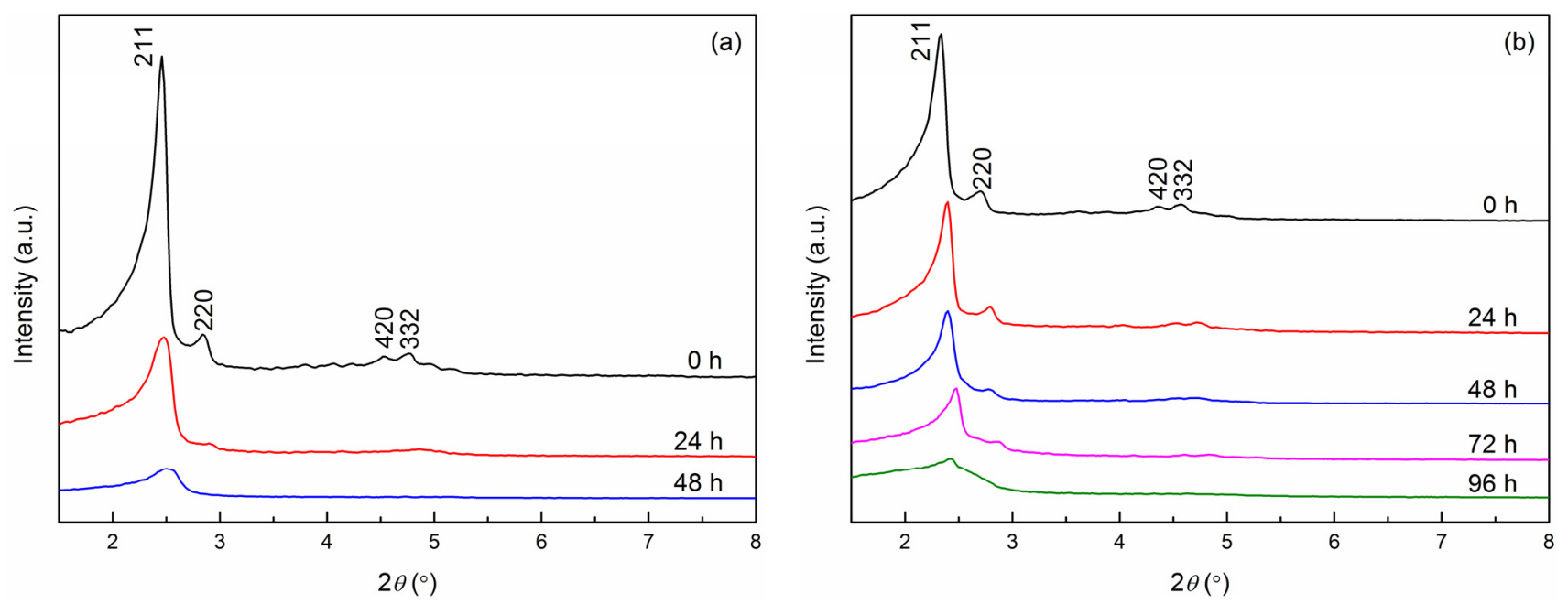

Figure 6. XRD patterns of the calcined (a) Si-MCM-48 and (b) V-Fe-MCM-48 samples after hydrothermal treatment at $110^{\circ} \mathrm{C}$ for different time.

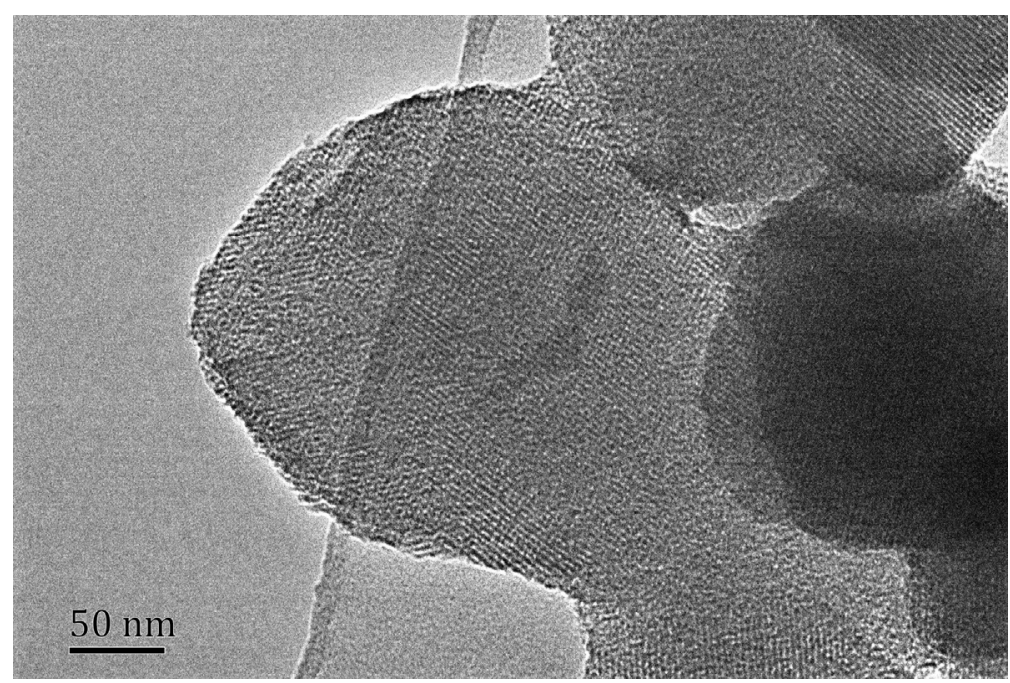

Figure 7. TEM image of the V-Fe-MCM-48 sample after $72 \mathrm{~h}$ hydrothermal treatment.

Also, in the hydrothermal stability test section the d-values are shifting with treatment time. For a deeper insight into the structural behavior, some structural parameters of the hydrothermally treated MCM-48 and V-Fe-MCM-48 samples at different time are given in Table 2, and a fitting of the data are shown in Figure 8. As displayed in Figure 8a, both the unit cell parameter an of MCM-48 and V-Fe-MCM-48 decrease with treatment time, suggesting a shrinkage of pore wall caused by the breakage of Si-O-Si bonds. Moreover, the a of V-Fe-MCM-48 decreases more significantly than that of MCM-48, together with a decreasing of metal content to some extent with the treating time found in Figure 8b, implying that most V and Fe species have been leached out from the silicate framework, which could be one of the reasons why the mesoporous structure becomes more disordered with time. Nevertheless, the $\mathrm{V}$ and Fe are still detected by ICP after $96 \mathrm{~h}$ treatment when the mesoporous structure has collapsed. Thus we proposed that doping heteroatoms played an important role in stabilizing the silicate framework at the prior hydrothermal treatment, and the mesoporous structure collapsed after $96 \mathrm{~h}$ may be due to the breakage of Si-O-Si bonds caused by the hydrogen bonds between water molecules and the $\mathrm{O}$ atoms in Si-O-Si bonds, which is the same as that of MCM-48. 

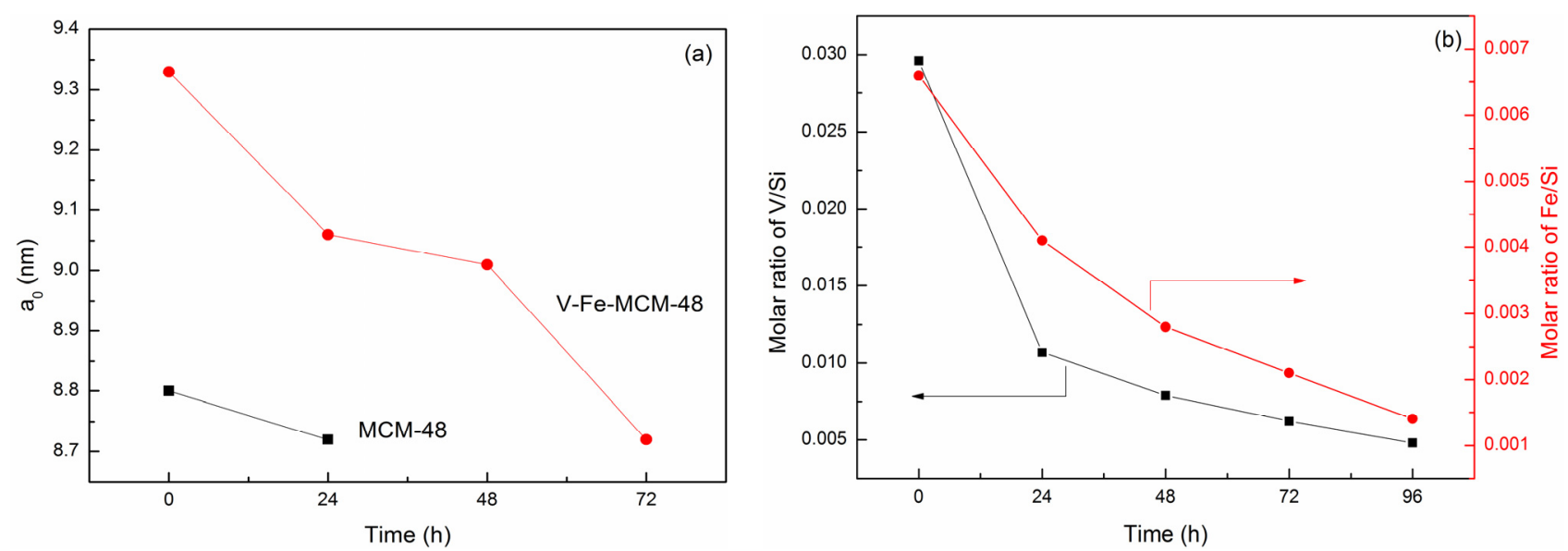

Figure 8. Development of (a) the unit cell parameter ao of MCM-48 and V-Fe-MCM-48 and (b) content of $\mathrm{V}$ and $\mathrm{Fe}$ in $\mathrm{V}-\mathrm{Fe}-\mathrm{MCM}-48$ with the time of hydrothermal treatment.

Table 2. Structural parameters of the Si- and V-Fe-MCM-48 samples with different treatment time.

\begin{tabular}{|c|c|c|c|c|c|c|}
\hline \multirow{2}{*}{ Time (h) } & \multicolumn{2}{|c|}{ MCM-48 } & \multicolumn{4}{|c|}{ V-Fe-MCM-48 } \\
\hline & $d_{211}(\mathrm{~nm})$ & $a_{0}{ }^{a}(n m)$ & V/Si ${ }^{a}$ (Molar Ratio) & $\mathrm{Fe} / \mathrm{Si}^{\mathrm{b}}$ (Molar Ratio) & $d_{211}(\mathrm{~nm})$ & $\mathbf{a}_{0}{ }^{a}(\mathrm{~nm})$ \\
\hline 0 & 3.59 & 8.80 & 0.0296 & 0.0066 & 3.81 & 9.33 \\
\hline 24 & 3.56 & 8.72 & 0.0107 & 0.0041 & 3.70 & 9.06 \\
\hline 48 & - & - & 0.0079 & 0.0028 & 3.68 & 9.01 \\
\hline 72 & - & - & 0.0062 & 0.0021 & 3.56 & 8.72 \\
\hline 96 & - & - & 0.0048 & 0.0014 & - & - \\
\hline
\end{tabular}

Notes: ${ }^{\text {a }}$ Unit cell parameter: $\mathrm{a}_{0}=6^{1 / 2} \mathrm{~d}_{211} ;{ }^{\mathrm{b}} \mathrm{ICP}$ results.

\section{Experimental Section}

\subsection{Materials}

Tetraethylorthosilicate (TEOS) was purchased from Sinopharm Chemical Reagent Co., Ltd.; cetyltrimethylammonium bromide (CTAB), ammonia solution (25-28 wt \%), ethanol, hydrogen peroxide $\left(\mathrm{H}_{2} \mathrm{O}_{2}, 30 \mathrm{wt} \%\right)$, vanadium metavanadate $\left(\mathrm{NH}_{4} \mathrm{VO}_{3}\right)$ and iron nitrate nonahydrate $\left(\mathrm{Fe}\left(\mathrm{NO}_{3}\right)_{3} \bullet 9 \mathrm{H}_{2} \mathrm{O}\right)$ were purchased from Nanjing Chemical Reagent Co., Ltd. (Nanjing, China).

\subsection{Synthesis of the Samples}

The V-Fe-MCM-48 was synthesized via one-step hydrothermal method under precisely control, using $\mathrm{CTAB}$ as structure-directing agent, and $\mathrm{EtOH}$ as cosolvent. The reaction was carried out at room temperature. The molar ratio composition of the reaction mixture was 1.0TEOS:0.3CTAB:60EtOH: $10 \mathrm{NH}_{3}: 0.04 \mathrm{~V}: 0.01 \mathrm{Fe}: 410 \mathrm{H}_{2} \mathrm{O}$, and the obtained sample was noted as V-Fe-MCM-48. A typical preparation of $\mathrm{V}-\mathrm{Fe}-\mathrm{MCM}-48$ is as follow: $0.0432 \mathrm{~g} \mathrm{NH}_{4} \mathrm{VO}_{3}$ and $0.0381 \mathrm{~g} \mathrm{Fe}\left(\mathrm{NO}_{3}\right)_{3} \cdot 9 \mathrm{H}_{2} \mathrm{O}$ were dissolved in $10 \mathrm{~mL}$ deionized water, respectively. Meanwhile, $1.0125 \mathrm{~g}$ CTAB was dissolved in $50 \mathrm{~mL}$ deionized water under mechanical stirring at $170 \mathrm{rpm}$, followed by adding $32.4 \mathrm{~mL}$ EtOH and $6.3 \mathrm{~mL}$ 25-28 wt \% ammonium solution orderly. When complete dissolution, the $\mathrm{NH}_{4} \mathrm{VO}_{3}$ solution and $\mathrm{Fe}\left(\mathrm{NO}_{3}\right)_{3}$ solution were added dropwise successively to the template solution under mechanical stirring 
at $450 \mathrm{rpm}$. After $15 \mathrm{~min}$ stirring, $2.1 \mathrm{~mL}$ TEOS was added dropwise to the above mixture solution, and kept on being further stirred for $2 \mathrm{~h}$. Then the synthesized gel was placed in the teflon-lined autoclave and aged at $100{ }^{\circ} \mathrm{C}$ for $24 \mathrm{~h}$. The sample was washed with deionized water and EtOH till neutral, and dried at $70{ }^{\circ} \mathrm{C}$ in air for $10 \mathrm{~h}$. The as-synthesized product was calcined at $550{ }^{\circ} \mathrm{C}$ in a flow of air for $6 \mathrm{~h}$ at a heating rate of $1{ }^{\circ} \mathrm{C} / \mathrm{min}$ to remove the template. For comparison, Si-MCM-48 samples were also synthesized using the same method.

\subsection{Characterization}

The XRD patterns of the samples were collected with Smartlab TM 9 KW (Rigaku Corporation, Tokyo, Japan) equipped with a rotating anode and $\mathrm{Cu} K \alpha$ radiation $(\lambda=0.154178 \mathrm{~nm})$.

Nitrogen adsorption-desorption isotherms were measured on a BELSORP-MINI analyzer (BEL Japan, Osaka, Janpan) at $77 \mathrm{~K}$. Before the measurements, calcined samples were degassed in vacuum at $200{ }^{\circ} \mathrm{C}$ for $2 \mathrm{~h}$. Surface areas were calculated using the BET equation and pore size distributions were obtained by the Barrett-Joyner-Halenda (BJH) method using desorption branch data.

The vanadium content and iron content in the samples were determined using a PE Optima 2000DV (PerkinElmer, Waltham, MA, USA) Inductively Coupling Plasma emission spectrometer (ICP). The samples were completely dissolved in hydrofluoric acid before analysis.

Field emission scanning electron microscopy (FE-SEM) was performed on a Hitachi S4800 Field Emission Scanning Electron Microscopy (Hitachi, Tokyo, Janpan).

Transmission electron microscopy (TEM) images were recorded on a JEM-2010 EX microscope (JEOL, Tokyo, Japan) operated at an accelerating voltage of $200 \mathrm{kV}$. The samples were crushed in A.R. grade ethanol, and the resulting suspension was allowed to dry on carbon film supported on copper grids.

Diffuse reflectance UV-vis spectra was recorded by a Lambda 950 spectrophotometer (PerkinElmer, Waltham, MA, USA) in the range of 200-800 nm with $\mathrm{Ba}_{2} \mathrm{SO}_{4}$ as reference.

The X-ray photoelectron spectra (XPS) were conducted on a PHI 5000 Versa Probe X-ray photoelectron spectrometer (ULVAC-PHI, Kanagawa, Japan) equipped with Al Karadiation (1486.6 eV). The $\mathrm{C} 1 \mathrm{~s}$ peak at $284.6 \mathrm{eV}$ was used as the reference for binding energies.

\subsection{Hydrothermal Stability Test}

The hydrothermal stability test was carried out as followed. Two grams of calcined sample was added to a teflon-lined autoclave with $100 \mathrm{~mL}$ distilled water. Then the autoclave was placed to a drying oven and treated at $110{ }^{\circ} \mathrm{C}$ for different time $(24,48,72$, and $96 \mathrm{~h}$ ). The sample was recovered by filtration and dried at $70{ }^{\circ} \mathrm{C}$ in air for $10 \mathrm{~h}$. To evaluate the hydrothermal stability, XRD was used to characterize the structure.

\section{Conclusions}

In this paper, we have successfully synthesized vanadium and iron co-doped MCM-48 with spherical morphology, narrow pore size distribution and high specific surface area by one-step hydrothermal method. Most of the vanadium and iron species were incorporated into the silicate 
framework as tetrahedral $\mathrm{V}^{4+}$ and $\mathrm{Fe}^{3+}$ species, respectively. The introduction of iron species reduced the particle sizes and increased the specific surface area significantly of V-MCM-48 with almost the same amount of vanadium species. Moreover, the hydrothermal stability of Si-MCM-48 improved by co-doping the silicate framework with $\mathrm{V}$ and Fe. We offer a direct and simple method to produce MCM-48 with remarkable hydrothermal stability, which promotes its usage in hot water and aqueous solution.

\section{Acknowledgments}

This project was supported by the National Natural Science Foundations of China (Grant No. 21276125, 20876077 and 21476108), the Program for Scientific Innovation Research of College Graduates in Jiangsu Province (CXZZ13_0443) and the Project of Priority Academic Program Development of Jiangsu Higher Education Institutions (PAPD).

\section{Author Contributions}

Wang Qian planed and conducted the experiments related to this study and discussed the obtained results; Haiqing Wang and Jin Chen assisted to check and modify the English language and style; Yan Kong established the framework of this paper. Four authors wrote the paper together.

\section{Conflicts of Interest}

The authors declare no conflict of interest.

\section{References}

1. Kresge, C.T.; Leonowicz, M.E.; Roth, W.J.; Vartuli, J.C.; Beck, J.S. Ordered mesoporous molecular-sieves synthesized by a liquid-crystal template mechanism. Nature 1992, 359, 710-712.

2. $\quad$ Egi, M.; Sugiyama, K.; Saneto, M.; Hanada, R.; Kato, K.; Akai, S. A mesoporous-silica-immobilized oxovanadium cocatalyst for the lipase-catalyzed dynamic kinetic resolution of racemic alcohols. Angew. Chem. Int. Ed. 2013, 52, 3654-3658.

3. Zhou, Y.; Lin, W.G.; Wan, M.M.; Yang, J.; Zhu, J.H. Novel selective adsorbent derived from hierarchical rockery-like MCM-41 monolith. J. Mater. Chem. 2012, 22, 23633-23641.

4. Wang, H.; Qian, W.; Chen, J.; Wu, Y.; Xu, X.; Wang, J.; Kong, Y. Spherical V-MCM-48: The synthesis, characterization and catalytic performance in styrene oxidation. RSC Adv. 2014, 4, 50832-50839.

5. Kim, T.W.; Kleitz, F.; Paul, B.; Ryoo, R. MCM-48-like large mesoporous silicas with tailored pore structure: Facile synthesis domain in a ternary triblock copolymer-butanol-water system. J. Am. Chem. Soc. 2005, 127, 7601-7610.

6. Gomez, S.; Garces, L.J.; Villegas, J.; Ghosh, R.; Giraldo, O.; Suib, S.L. Synthesis and characterization of TM-MCM-48 (TM = Mn, V, Cr) and their catalytic activity in the oxidation of styrene. J. Catal. 2005, 233, 60-67.

7. Suteewong, T.; Sai, H.; Cohen, R.; Wang, S.; Bradbury, M.; Baird, B.; Gruner, S.M.; Wiesner, U. Highly aminated mesoporous silica nanoparticles with cubic pore structure. J. Am. Chem. Soc. 2010, 133, 172-175. 
8. Alfredsson, V.; Anderson, M.W. Structure of MCM-48 revealed by transmission electron microscopy. Chem. Mater. 1996, 8, 1141-1146.

9. Zhao, W.; Qin, M.; Wang, L.N.; Chu, J.L.; Qu, J.K.; Li, S.H.; Li, Q.Z.; Qi, T. Synthesis of submicron spherical Fe-MCM-48 with actual gyroid like structure. J. Colloid Interface Sci. 2012, $384,81-86$.

10. Kim, T.W.; Chung, P.W.; Lin, V.S.Y. Facile synthesis of monodisperse spherical MCM-48 mesoporous silica nanoparticles with controlled particle size. Chem. Mater. 2010, 22, 5093-5104.

11. Hu, J.; Zhou, L.H.; Han, X.; Liu, H.L.; Hu, Y. The complex morphologies of Ti-MCM-41 templated by gemini surfactant. Mater. Res. Bull. 2007, 42, 102-112.

12. Chen, Y.; Shi, X.; Han, B.; Qin, H.; Li, Z.; Lu, Y.; Wang, J.; Kong, Y. The complete control for the nanosize of spherical MCM-41. J. Nanosci. Nanotechnol. 2012, 12, 7239-7249.

13. Liu, C.C.; Wang, X.M.; Lee, S.; Pfefferle, L.D.; Haller, G.L. Surfactant chain length effect on the hexagonal-to-cubic phase transition in mesoporous silica synthesis. Microporous Mesoporous Mater. 2012, 147, 242-251.

14. Selvam, P.; Dapurkar, S.E. Catalytic activity of highly ordered mesoporous VMCM-48. Appl. Catal. A 2004, 276, 257-265.

15. Han, B.; Wang, H.; Kong, Y.; Wang, J. Improvement on the mesostructural ordering and catalytic activity of Co-MCM-41 with ascorbic acid as auxiliary. Mater. Lett. 2013, 100, 159-162.

16. Ma, H.; Kong, Y.; Hou, W.; Yan, Q. Synthesis of ordered hexagonal porous tin-doped zirconium oxides with a high surface area. Microporous Mesoporous Mater. 2005, 77, 241-243.

17. Kong, Y.; Zhu, H.Y.; Yang, G.; Guo, X.F.; Hou, W.H.; Yan, Q.J.; Gu, M.; Hu, C. Investigation of the structure of MCM-41 samples with a high copper content. Adv. Funct. Mater. 2004, 14, 816-820.

18. Betiha, M.A.; Hassan, H.M.A.; Al-Sabagh, A.M.; Khder, A.E.R.S.; Ahmed, E.A. Direct synthesis and the morphological control of highly ordered mesoporous AlSBA-15 using urea-tetrachloroaluminate as a novel aluminum source. J. Mater. Chem. 2012, 22, 17551-17559.

19. Piumetti, M.; Armandi, M.; Garrone, E.; Bonelli, B. An IR spectroscopy assessment of the surface acidity of mesoporous $\mathrm{VO}_{\mathrm{x}}-\mathrm{SiO}_{2}$ catalysts. Microporous Mesoporous Mater. 2012, 164, 111-119.

20. Samanta, S.; Das, S.; Samanta, P.K.; Dutta, S.; Biswas, P. A mononuclear copper(II) complex immobilized in mesoporous silica: An efficient heterogeneous catalyst for the aerobic oxidation of benzylic alcohols. Rsc Adv. 2013, 3, 19455-19466.

21. Zhang, G.; Long, J.; Wang, X.; Zhang, Z.; Dai, W.; Liu, P.; Li, Z.; Wu, L.; Fu, X. Catalytic role of $\mathrm{Cu}$ sites of $\mathrm{Cu} / \mathrm{MCM}-41$ in phenol hydroxylation. Langmuir 2010, 26, 1362-1371.

22. Lou, L.L.; Jiang, S.; Yu, K.; Gu, Z.; Ji, R.; Dong, Y.; Liu, S. Mesoporous silicas functionalized with aminopropyl via co-condensation: Effective supports for chiral $\mathrm{Mn}(\mathrm{III})$ salen complex. Microporous Mesoporous Mater. 2011, 142, 214-220.

23. Xiong, H.; Pham, H.N.; Datye, A.K. Hydrothermally stable heterogeneous catalysts for conversion of biorenewables. Green Chem. 2014, 16, 4627-4643.

24. Wang, J.; Fan, D.; Yu, T.; Wang, J.; Hao, T.; Hu, X.; Shen, M.; Li, W. Improvement of low-temperature hydrothermal stability of $\mathrm{Cu} / \mathrm{SAPO}-34$ catalysts by $\mathrm{Cu}^{2+}$ species. J. Catal. 2015, 322, 84-90.

25. Xia, Y.; Mokaya, R. Enhanced hydrothermal stability of Al-grafted MCM-48 prepared via various alumination routes. Microporous Mesoporous Mater. 2004, 74, 179-188. 
26. Li, Q.; Wu, Z.; Tu, B.; Park, S.S.; Ha, C.-S.; Zhao, D. Highly hydrothermal stability of ordered mesoporous aluminosilicates Al-SBA-15 with high Si/Al ratio. Microporous Mesoporous Mater. 2010, 135, 95-104.

27. Pan, D.; Yuan, P.; Zhao, L.; Liu, N.; Zhou, L.; Wei, G.; Zhang, J.; Ling, Y.; Fan, Y.; Wei, B.; et al. New understanding and simple approach to synthesize highly hydrothermally stable and ordered mesoporous materials. Chem. Mater. 2009, 21, 5413-5425.

28. Wang, J.; Ge, H.; Bao, W. Synthesis and characteristics of SBA-15 with thick pore wall and high hydrothermal stability. Mater. Lett. 2015, 145, 312-315.

29. Zhang, Z.; Han, Y.; Zhu, L.; Wang, R.; Yu, Y.; Qiu, S.; Zhao, D.; Xiao, F.S. Strongly acidic and high-temperature hydrothermally stable mesoporous aluminosilicates with ordered hexagonal structure. Angew. Chem. Int. Ed. 2001, 40, 1258-1262.

30. Jun, S.; Kim, J.M.; Ryoo, R.; Ahn, Y.S.; Han, M.H. Hydrothermal stability of MCM-48 improved by post-synthesis restructuring in salt solution. Microporous Mesoporous Mater. 2000, 41, 119-127.

31. Cao, L.; Zhao, X.; Jin, J.; Xu, C.; Gao, X.; Lan, L.; Yuan, X.; Liu, H.; Liu, H. Crystal-seeds-based strategy for the synthesis of hydrothermally stable mesoporous aluminosilicates with a largely decreased $\mathrm{H}_{2} \mathrm{O}$ amount. Ind. Eng. Chem. Res. 2014, 53, 17286-17293.

32. Xu, X.Y.; Kong, Y.; Chen, Y.; Zhao, N.; Shi, X.B.; Wang, J. Facile synthesis of spherical V-MCM-48. Chin. J. Inorg. Chem. 2012, 28, 2478-2484.

33. Kong, Y.; Zhang, R.; Xu, X.; Wang, Z.; Wang, J. Synthesis and characterization of V-MCM41 with high vanadium content. Chin. J. Inorg. Chem. 2008, 24, 1124-1127.

34. Wu, Y.; Zhang, Y.; Cheng, J.; Li, Z.; Wang, H.; Sun, Q.; Han, B.; Kong, Y. Synthesis, characterization and catalytic activity of binary metallic titanium and iron containing mesoporous silica. Microporous Mesoporous Mater. 2012, 162, 51-59.

35. Zhang, Y.; Gao, F.; Wan, H.; Wu, C.; Kong, Y.; Wu, X.; Zhao, B.; Dong, L.; Chen, Y. Synthesis, characterization of bimetallic Ce-Fe-SBA-15 and its catalytic performance in the phenol hydroxylation. Microporous Mesoporous Mater. 2008, 113, 393-401.

36. Jiang, S.; Kong, Y.; Wang, J.; Ren, X.; Yan, Q. Synthesis, characterization of bimetallic Sn-Zn-MCM41 and its catalytic performance in the hydroxylation of phenol. J. Porous Mat. 2006, 13, 341-346.

37. Kong, Y.; Jiang, S.; Wang, J.; Wang, S.; Yan, Q.; Lu, Y. Synthesis and characterization of Cu-Ti-MCM41. Microporous Mesoporous Mater. 2005, 86, 191-197.

38. He, N.; Lu, Z.; Yuan, C.; Hong, J.; Yang, C.; Bao, S.; Xu, Q. Effect of trivalent elements on the thermal and hydrothermal stability of MCM-41 mesoporous molecular materials. Supramol. Sci. 1998, 5, 553-558.

39. Kumar, D.; Pillai, K.T.; Sudersanan, V.; Dey, G.K.; Gupta, N.M. Hydrothermal synthesis and characterization of uranium-containing MCM-48 samples. Chem. Mater. 2003, 15, 3859-3865.

40. Brunauer, S.; Deming, L.S.; Deming, W.E.; Teller, E. On a theory of the van der waals adsorption of gases. J. Am. Chem. Soc. 1940, 62, 1723-1732.

41. Greenwood, N.N.; Earnshaw, A. Chemistry of the Elements, 2nd ed.; Butterworth-Heinemann: Oxford, UK 1997; p. 984.

42. Vekilov, P.G. Nucleation. Cryst. Growth Des. 2010, 10, 5007-5019.

43. Kashchiev, D.; van Rosmalen, G.M. Review: Nucleation in solutions revisited. Cryst. Res. Technol. 2003, 38, 555-574. 
44. Maneesuwan, H.; Chaisuwan, T.; Wongkasemjit, S. Synthesis of Fe-Ti-MCM-48 from silatrane precursor via sol-gel process and its hydrothermal stability. Mater. Chem. Phys. 2014, 146, 374-379.

45. Maneesuwan, H.; Longloilert, R.; Chaisuwan, T.; Wongkasemjit, S. Synthesis and characterization of Fe-Ce-MCM-48 from silatrane precursor via sol-gel process. Mater. Lett. 2013, 94, 65-68.

46. Hu, L.; Yue, B.; Wang, C.; Chen, X.; He, H. Enhanced catalytic activity over vanadium-containing silylated SBA-15 catalysts for styrene epoxidation and benzene hydroxylation. Appl. Catal. A 2014, 477, 141-146.

47. Gao, F.; Zhang, Y.H.; Wan, H.Q.; Kong, Y.; Wu, X.C.; Dong, L.; Li, B.Q.; Chen, Y. The states of vanadium species in V-SBA-15 synthesized under different $\mathrm{pH}$ values. Microporous Mesoporous Mater. 2008, 110, 508-516.

48. Zhao, W.; Luo, Y.F.; Deng, P.; Li, Q.Z. Synthesis of Fe-MCM-48 and its catalytic performance in phenol hydroxylation. Catal. Lett. 2001, 73, 199-202.

49. Zhang, H.; Tang, C.; Sun, C.; Qi, L.; Gao, F.; Dong, L.; Chen, Y. Direct synthesis, characterization and catalytic performance of bimetallic Fe-Mo-SBA-15 materials in selective catalytic reduction of $\mathrm{NO}$ with $\mathrm{NH}_{3}$. Microporous Mesoporous Mater. 2012, 151, 44-55.

50. Hess, C.; Wild, U.; Schlögl, R. The mechanism for the controlled synthesis of highly dispersed vanadia supported on silica SBA-15. Microporous Mesoporous Mater. 2006, 95, 339-349.

51. De Stefanis, A.; Kaciulis, S.; Pandolfi, L. Preparation and characterization of Fe-MCM-41 catalysts employed in the degradation of plastic materials. Microporous Mesoporous Mater. 2007, 99 , 140-148.

52. Yamashita, T.; Hayes, P. Analysis of XPS spectra of $\mathrm{Fe}^{2+}$ and $\mathrm{Fe}^{3+}$ ions in oxide materials. Appl. Surf. Sci. 2008, 254, 2441-2449.

(C) 2015 by the authors; licensee MDPI, Basel, Switzerland. This article is an open access article distributed under the terms and conditions of the Creative Commons Attribution license (http://creativecommons.org/licenses/by/4.0/). 